\title{
High cyclin BI expression is associated with poor survival in breast
}

\section{cancer}

\author{
K Aaltonen ${ }^{*, 1,2}$, R-M Amini ${ }^{3}$, P Heikkilä ${ }^{4}$ K Aittomäki ${ }^{5}$, A Tamminen ${ }^{2}$, H Nevanlinna ${ }^{2}$ and C Blomqvist ${ }^{1,6}$ \\ 'Department of Oncology, Helsinki University Central Hospital, P.O. Box 180, Helsinki Fl-00029 HUS, Finland; ${ }^{2}$ Department of Obstetrics and \\ Gynaecology, Helsinki University Central Hospital, P.O. Box 140, Helsinki Fl-00029 HUS, Finland; ${ }^{3}$ Department of Genetics and Pathology, Uppsala \\ University Hospital, Uppsala SE-75 185, Sweden; ${ }^{4}$ Department of Pathology, Helsinki University Central Hospital, P.O. Box 400, Helsinki Fl-00029 HUS, \\ Finland; ${ }^{5}$ Department of Clinical Genetics, Helsinki University Central Hospital, P.O. Box 140, Helsinki Fl-00029 HUS, Finland; ${ }^{6}$ Department of Oncology, \\ Radiology and Clinical Immunology, Uppsala University Hospital, Uppsala SE-75 I85, Sweden
}

Cyclin $\mathrm{BI}$ regulates the $\mathrm{G}_{2}-\mathrm{M}$ transition of the cell cycle. Cyclin $\mathrm{BI}$ expression is higher in premalignant and malignant than normal breast lesions. Correlation of cyclin BI expression with other histopathological variables and prognostic role in breast cancer are not fully understood. Traditionally used prognostic criteria identify large subset of patients to receive adjuvant chemotherapy and to be exposed to adverse effects. A reliable and simple method helping prognostic evaluation in breast cancer is needed. We analysed cyclin BI expression on 1348 invasive breast cancers and studied correlations with other histopathological variables and survival. High cyclin BI correlated with high tumour grade, large tumour size and positive nodal status, oestrogen and progesterone receptor negativity, positive HER2 and p53 status, young age at diagnosis, and high cyclin E, cyclin A and Ki67 expression. Among patients not given adjuvant chemotherapy high cyclin $\mathrm{BI}$ was a strong predictor of shorter overall and metastasis-free survival $(R R 3.74, P<0.0005$ and $R R$ 3.5 I, $P<0.0005$, respectively), and remained as an independent prognostic factor also in multivariate analysis (RR I.80, $P=0.04$ and RR 2.3I, $P=0.02$, respectively). This study suggests high cyclin $B I$ associates with aggressive phenotype and is an independent prognostic factor in breast cancer.

British Journal of Cancer (2009) I 00, 1055-1060. doi: I0.1038/sj.bjc.6604874 www.bjcancer.com

Published online 17 March 2009

(c) 2009 Cancer Research UK

Keywords: breast cancer; cyclin BI; survival; prognosis

Breast cancer is a heterogeneous disease with varying biological profile and aggressiveness. Adjuvant chemotherapy improves breast cancer survival but can cause side effects that may potentially have negative long-term effects on quality of life of women surviving breast cancer. Therefore additional markers are needed for better selection of the patients benefiting from adjuvant treatment and to avoid overtreatment. Traditional prognostic factors, such as tumour size, lymph node status and tumour grade are used to identify patients with high risk for recurrence who potentially benefit from adjuvant chemotherapy (Bast et al, 2001). Negative hormone receptor and positive HER2 status also predict poor outcome. A new entity, the so-called triple negative (oestrogen receptor, progesterone receptor and HER2 negative) breast cancer has a highly aggressive clinical course with shorter recurrence-free and overall survival (Dent et al, 2007). High proliferation rate has also been shown to associate with poor breast cancer survival (Dettmar et al, 1997; Bryant et al, 1998; Ahlin et al, 2007). Newer methods utilising complementary DNA (cDNA) have been developed aiming at more specific prognostic evaluation than by immunohistochemical methods (van de Vijver et al, 2002; van't Veer et al, 2002; Paik et al, 2004). These methods are laborious and expensive, and are not as easily adapted for routine use as are immunohistochemical methods.

*Correspondence: Dr K Aaltonen; E-mail: kirsimari.aaltonen@helsinki.fi Revised 8 December 2008; accepted 10 December 2008; published online 17 March 2009
Carefully regulated expression of cyclins and cyclin-dependent kinases controls the cell cycle (Sherr, 1996). The cyclin B1/CDK1 complex controls the $\mathrm{G}_{2}-\mathrm{M}$ phase transition, and is needed for initiation of mitosis (Pines and Hunter, 1990). Deregulation of cyclin B1 causes uncontrolled cell growth and may promote malignant transformation. p53 regulates $\mathrm{G}_{2}-\mathrm{M}$ transition through cyclin B1 expression level (Innocente et al, 1999). In cancer cells, cyclin $\mathrm{B} 1$ expression has also been detected in $\mathrm{G}_{1}$ phase (Shen et al, 2004). This continuous, unscheduled expression may lead to substrate phosphorylation regardless of the cell-cycle phase and thus cause uncontrolled cell-cycle progression and be one of the mechanisms in genetic instability and carcinogenesis.

Cyclin B1 overexpression is common in several cancers (Murakami et al, 1999; Soria et al, 2000; Nozoe et al, 2002; Takeno et al, 2002; Yoshida et al, 2004; Ikuerowo et al, 2006). It has been shown to associate with high-grade tumours and advanced stage of disease, as well as poor prognosis, in several cancers including oesophageal squamous cell (Murakami et al, 1999; Nozoe et al, 2002; Takeno et al, 2002), non-small cell lung (Soria et al, 2000; Yoshida et al, 2004) and renal cell cancer (Ikuerowo et al, 2006).

Cyclin B1 expression level increases in the transition from benign through premalignant to advanced malignant breast lesions (Kawamoto et al, 1997). The first reported study of cyclin B1 expression in breast cancer comprised only 73 cancers (Winters et al, 2001). Both nuclear and cytoplasmic expressions were independent predictors of poor relapse-free and overall survival. Cyclin B1 expression was not associated with tumour size, nodal 
status, grade, oestrogen receptor (ER) status or p53 immunohistochemical expression. In another study with 332 T1-2 N-negative breast cancers (Kühling et al, 2003; Rudolph et al, 2003), high cyclin B1 expression associated with high grade, high Ki67, cyclin $A$ and E expression, and ER and progesterone receptor (PR) negativity and predicted relapse-free and overall survival in univariate analysis but was not an independent prognostic factor in multivariate analysis including $\mathrm{Ki} 67$ as a covariate (Rudolph et al, 2003). Among the 273 tumours treated with surgery and postoperative radiation only, cyclin B1 was an independent predictor of poor overall survival among premenopausal but not postmenopausal or all patients (Kühling et al, 2003). A further study with 56 invasive stage I-II cancers did not show any association between cyclin B1 expression and prognosis (Peters et al, 2004). A recent study with 109 breast cancers suggested that nuclear cyclin B1 expression was an independent prognostic factor (Suzuki et al, 2007).

The studies of cyclin B1 expression in breast cancer strongly suggest a prognostic role but these studies have been rather small. In this study we investigated cyclin B1 expression, its correlation with other histopathological features and survival in an extensive series of 1348 breast cancers (779 cancers in survival analysis).

\section{MATERIALS AND METHODS}

\section{Patients}

The study consists of 1348 invasive breast cancers. Of these, 884 are unselected patients treated at the Department of Oncology, Helsinki University Central Hospital between 1997-1998 and 2000 (79\% of all consecutive, newly diagnosed breast cancer cases during the collection periods; Syrjäkoski et al, 2000; Kilpivaara et al, 2005). The rest of the patients are familial breast cancer patients identified by systematic screening at the Department of Oncology, Helsinki University Central Hospital or ascertained through genetic counselling at the Department of Clinical Genetics (Eerola et al, 2000). Of all patients, 439 are sporadic, 456 have strong family history (at least three first or second degree relatives with breast or ovarian cancer, including the proband), 342 have family history of two affected first degree relatives (including the proband) and 53 patients are BRCA1 and 58 BRCA2 mutation carriers.

Information on tumour histology, grade, size, nodal status, distant metastases, ER and PR status were obtained from pathology reports (Eerola et al, 2005). An expert breast cancer pathologist re-reviewed all tumours for histology and grade. Grading was performed according to Scarff-Bloom-Richardson modified by Elston and Ellis. Patient characteristics are shown in Table 1. Tissue microarray (TMA) construction has been described earlier (Eerola et al, 2005). HER2 expression was analysed by immunohistochemical staining and gene amplification by chromogenic in situ hybridisation on TMAs (Tanner et al, 2000; Lassus et al, 2004), and p53 (Tommiska et al, 2005), cyclin A (Aaltonen et al, 2006) and Ki67 (Ahlin et al, 2007) protein expression by immunohistochemical staining as previously described.

\section{Immunohistochemistry}

After deparaffinisation in xylene and hydration in graded alcohols, cyclin B1 immunostaining was done in automated immunostainer (Ventana Medical Systems Inc., Tucson, AZ, USA) using a diaminobenzidine kit and amplification kit (Ventana) to ensure standardised performance. Cyclin B1 antibody (Novocastra, Newcastle-upon-Tyne, UK) was diluted 1:40 and antigen retrieval was done using the iView kit (Ventana). Only unequivocal positive nuclear or cytoplasmic staining was accepted as a positive reaction, and cyclin B1 result was the percentage of tumour cells displaying cytoplasmic or nuclear
Table I Patient and tumour characteristics

\begin{tabular}{|c|c|}
\hline \multicolumn{2}{|l|}{ Grade } \\
\hline 1 & $318(23.6 \%)$ \\
\hline 2 & $606(45.0 \%)$ \\
\hline 3 & $399(29.6 \%)$ \\
\hline Not known & $25(1.9 \%)$ \\
\hline \multicolumn{2}{|l|}{ Tumour size (T) } \\
\hline I & $782(58.0 \%)$ \\
\hline 2 & $448(33.2 \%)$ \\
\hline 3 & $51(3.8 \%)$ \\
\hline 4 & $38(2.8 \%)$ \\
\hline NA & $29(2.2 \%)$ \\
\hline \multicolumn{2}{|l|}{ Nodal status (N) } \\
\hline Positive & 585 (43.4\%) \\
\hline Negative & $731(54.2 \%)$ \\
\hline NA & $32(2.4 \%)$ \\
\hline \multicolumn{2}{|c|}{ Primary metastases (N) } \\
\hline Positive & 48 (3.6\%) \\
\hline Negative & $1244(92.3 \%)$ \\
\hline NA & $56(4.2 \%)$ \\
\hline \multicolumn{2}{|l|}{ Clinical stage } \\
\hline I & $503(37.3 \%)$ \\
\hline ॥ & $659(48.9 \%)$ \\
\hline III & $58(4.3 \%)$ \\
\hline IV & $48(3.6 \%)$ \\
\hline NA & $80(5.9 \%)$ \\
\hline \multicolumn{2}{|c|}{ Oestrogen receptor (ER) } \\
\hline Positive & 989 (73.4\%) \\
\hline Negative & $288(21.4 \%)$ \\
\hline NA & $71(5.3 \%)$ \\
\hline \multicolumn{2}{|c|}{ Progesterone receptor (PR) } \\
\hline Positive & $828(61.4 \%)$ \\
\hline Negative & 448 (33.2\%) \\
\hline NA & $72(5.3 \%)$ \\
\hline \multicolumn{2}{|l|}{ Tumour pathology } \\
\hline Ca ductale & $924(68.5 \%)$ \\
\hline Ca lobulare & $254(18.8 \%)$ \\
\hline Ca medullare & $20(1.5 \%)$ \\
\hline Ca mucinosum & $25(1.9 \%)$ \\
\hline Ca papillare & $4(0.3 \%)$ \\
\hline Ca tubulare & $46(3.4 \%)$ \\
\hline Others & $75(5.6 \%)$ \\
\hline \multicolumn{2}{|l|}{ HER2 } \\
\hline Positive & $155(\mid 1.5 \%)$ \\
\hline Negative & 1074 (79.7\%) \\
\hline NA & $119(8.8 \%)$ \\
\hline \multicolumn{2}{|l|}{ p53 } \\
\hline Positive & $253(18.8 \%)$ \\
\hline Negative & 989 (73.4\%) \\
\hline NA & $106(7.9 \%)$ \\
\hline \multicolumn{2}{|l|}{ Ki67 expression } \\
\hline$<5 \%$ & $318(23.6 \%)$ \\
\hline $5-19 \%$ & $553(41.0 \%)$ \\
\hline $20-29 \%$ & $220(16.3 \%)$ \\
\hline$>29 \%$ & $214(15.9 \%)$ \\
\hline NA & 43 (3.2\%) \\
\hline \multicolumn{2}{|l|}{ Age at diagnosis } \\
\hline$<50$ years & $493(36.6 \%)$ \\
\hline$\geqslant 50$ years & $855(63.4 \%)$ \\
\hline \multicolumn{2}{|l|}{ Menopausal status } \\
\hline Premenopausal & 297 (22.0\%) \\
\hline Postmenopausal & $568(42.1 \%)$ \\
\hline NA & 483 (35.8\%) \\
\hline
\end{tabular}


immunoreactivity. Normal breast tissue specimen was used as negative and human palatine tonsil tissue specimen as positive control for cyclin B1. Minimum of 500 tumour cells on each tumour was calculated ( $\times 40$ objective). One investigator analysed the TMAs. All scoring was done under the supervision of an expert breast cancer pathologist. Result was obtained from 1100 tumours (81.4\%). Cyclin B1 median value was $5.0 \%$, range $0-71.5 \%$, standard deviation 6.39 and standard error 0.19. Cyclin B1 expression followed the normal distribution.

\section{The follow-up data}

Information on adjuvant treatment and distant metastases during the follow-up was collected from the patient records. The information on death due to breast cancer or other reason was obtained from the Finnish Cancer Registry. Survival was analysed as metastasis-free survival (MFS): the time from the date of primary surgery to the date of radiological confirmed distant metastases, and as overall survival (OS): the time from the date of primary surgery to the date of death due to breast cancer. A total of 797 patients were accepted for survival analysis: including the unselected series and familial patients ascertained to the familial breast cancer study at the diagnosis or within 6 months after diagnosis. Of these 797 patients, 796 (99.9\%) underwent surgery, $691(87 \%)$ received adjuvant radiotherapy, $323(41 \%)$ adjuvant chemotherapy and $359(45 \%)$ adjuvant endocrine treatment. Of the patients that were given adjuvant chemotherapy, 163 (50\%) were treated with CMF (cyclophosphamide-methotrexate-5-fluorouracil), 102 (32\%) with CEF (cyclophosphamide-epirubicin-5fluorouracil) and 58 (18\%) with some other chemotherapy regimen. Chemotherapy, endocrine treatment and radiation were given postoperative. Treatment decisions were made according to standard guidelines at that time. The median follow-up time was 93 months (2-516 months). Of all the patients in the survival analysis, $127(16 \%)$ relapsed with distant metastases during the follow-up time, of whom 91 (11\%) died from breast cancer.

\section{Statistical analyses}

Statistical analyses were assessed with SPSS for Windows v12.0.1 (SPSS Inc., Chicago, IL, USA) and SISA (http://home.clara.net/sisa/). Correlation of cyclin B1 expression (as a continuous variable) and other histopathological features was assessed with Mann-Whitney $U$-test (dichotomised variables) or Spearman's $\sigma$-correlation test (continuous variables). The frequencies of cyclin B1 positive tumours among patient groups with different familial background were compared with $\chi^{2}$-test. A study investigating the optimal cut-off values of cyclin A and Ki67 for prognostic evaluation suggested that cut-off value around the 7th decile gives best separation between slowly and rapidly proliferating tumours (Ahlin et al, 2007). The relative risk (RR) for MFS and OS with 95\% confidence interval (CI) using the Cox proportional hazard model was calculated for cyclin B1 dichotomised at 7th decile (cut-off value 5.6\%). Kaplan-Meier curves were constructed for survival comparing the subsets of cases using a log-rank test. All $P$-values are two-sided and significance level is 0.05 .

\section{Ethics}

This study was performed with informed consent from the patients as well as permission from the Ethics Committee of the Helsinki University Central Hospital and from the Ministry of Social Affairs and Health in Finland.

\section{RESULTS}

High cyclin B1 expression was associated with large tumour size, positive nodal status, advanced clinical stage, high grade, ER and
Table 2 Correlation of cyclin B। expression and other tumour characteristics (Spearman's $\sigma$-correlation test)

\begin{tabular}{lccc}
\hline & $\begin{array}{c}\text { Correlation } \\
\text { coefficient }\end{array}$ & $\mathbf{9 5 \%} \mathbf{~ C l}$ & P value \\
\hline Tumour size (T) & 0.163 & $0.104-0.221$ & $<0.0005$ \\
Nodal status (N) & 0.081 & $0.021-0.140$ & 0.008 \\
Primary metastases (M) & 0.018 & $-0.042-0.078$ & 0.56 \\
Clinical stage & 0.129 & $0.075-0.183$ & $<0.0005$ \\
Tumour grade & 0.493 & $0.447-0.537$ & $<0.0005$ \\
Oestrogen receptor (ER) & -0.327 & $-0.380--0.272$ & $<0.0005$ \\
Progesterone receptor (PR) & -0.216 & $-0.273--0.157$ & $<0.0005$ \\
HER2 & 0.245 & $0.188-0.301$ & $<0.0005$ \\
Triple negativity & -0.275 & $-0.329--0.220$ & $<0.0005$ \\
Ki67 & 0.528 & $0.484-0.570$ & $<0.0005$ \\
P53 & 0.311 & $0.256-0.364$ & $<0.0005$ \\
Age at onset & -0.156 & $-0.213--0.098$ & $<0.0005$ \\
Menopausal status & -0.164 & $-0.228--0.098$ & $<0.0005$ \\
Cyclin E & 0.392 & $0.340-0.442$ & $<0.0005$ \\
Cyclin D & 0.021 & $-0.039-0.081$ & 0.50 \\
Cyclin A & 0.610 & $0.571-0.646$ & $<0.0005$ \\
\hline Abbrevati & &
\end{tabular}

Abbreviation: $95 \% \mathrm{Cl}=95 \%$ confidence interval. Cyclin BI analysed as a continuous variable. $* P$ value assessed with the Mann-Whitney U-test.

Table 3 Cyclin BI expression and survival in univariate analysis (Cox regression analysis)

\begin{tabular}{lccc}
\hline & RR & $\mathbf{9 5 \%} \mathbf{C l}$ & P value \\
\hline (A) Metastasis-free survival & & & \\
$\quad$ Chemotherapy naive patients $(n=473)$ & 3.51 & $2.05-6.01$ & $<0.0005$ \\
$\quad$ All patients $(n=797)$ & 2.48 & $1.72-3.57$ & $<0.0005$ \\
Chemotherapy patients $(n=323)$ & 1.58 & $0.96-2.60$ & 0.07 \\
& & & \\
(B) Overall survival & & & \\
Chemotherapy naive patients $(n=473)$ & 3.74 & $1.96-7.12$ & $<0.0005$ \\
All patients $(n=797)$ & 2.58 & $1.82-3.90$ & $<0.0005$ \\
Chemotherapy patients $(n=323)$ & 1.56 & $0.87-2.80$ & 0.13 \\
\hline
\end{tabular}

Abbreviations: $\mathrm{RR}=$ relative risk; $95 \% \mathrm{Cl}=95 \%$ confidence interval. Cyclin $\mathrm{B}$ । dichotomised at 7 th percentile $(5.6 \%)$.

PR negativity, positive p53, HER2, and Ki67 status, high cyclin A and cyclin E expression, younger age at disease onset, and premenopausal status. Furthermore high cyclin B1 expression was significantly more common among triple-negative tumours. Cyclin B1 and D1 expressions did not correlate. Table 2 shows the correlations between cyclin B1 and other tumour features. Ductal and medullary histology were significantly more common among tumours with high than low cyclin B1 expression $(P<0.0005$ and $P=0.0008$, respectively), and lobular histology among tumours with low cyclin $\mathrm{B} 1$ expression $(P<0.0005)$.

Tumours with the highest cyclin B1 expression ( $>10 \%)$ were more frequent among BRCA1 than sporadic (OR 2.8, 95\% CI $1.4-5.6, P=0.003$ ) or familial BRCA1/2 mutation negative (OR 4.8, 95\% CI 2.3-9.9, $P<0.0005)$ patients. Cyclin B1 expression among BRCA2-related tumours did not significantly differ from expression among tumours of sporadic or familial non-BRCA1/2 patients but tumours of sporadic patients showed more often cyclin B1 expression above $10 \%$ than tumours of familial non-BRCA1/2 patients (OR 1.7, 95\% CI 1.1-2.7, $P=0.02$ ).

The RRs for OS and MFS were assessed with cyclin B1 dichotomised at 7 th decile $(5.6 \%)$, because we have earlier shown that this is the optimal cut-off for proliferation markers (Ahlin et al, 2007). This corresponds to the proportion of grade 3 tumours in our material. The RR for poor survival was 3.74 (95\% CI 1.967.12, $P<0.0005)$ and for metastasis 3.51 (95\% CI 2.05-6.01, $P<0.0005$ ) among chemotherapy-naive patients (Table 3). Among 

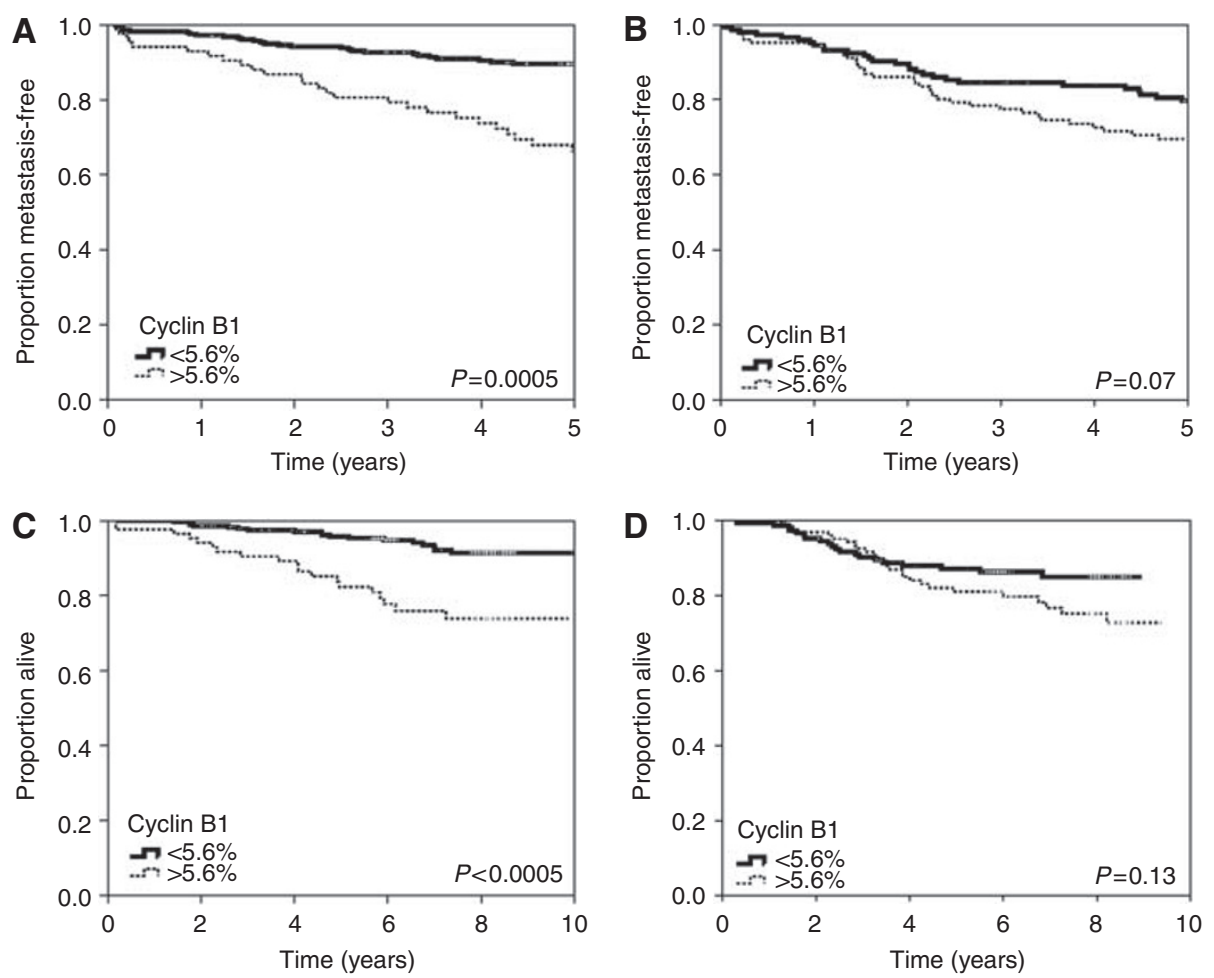

Figure I Kaplan-Meier curves showing metastasis-free and overall survival for cyclin BI dichotomised at 5.6\% (7th decile). (A) Metastasis-free survival among chemotherapy-naive patients $(n=473)$. (B) Metastasis-free survival among patients having received adjuvant chemotherapy $(n=323)$. (C) Overall survival among chemotherapy-naive patients $(n=473)$. (D) Overall survival among patients having received adjuvant chemotherapy $(n=473)$. KaplanMeier curves constructed and P-values counted comparing the subsets of cases using a log-rank test.

the subgroup of patients that had received chemotherapy, the association with poor MFS was weaker (RR $1.58,95 \%$ CI $0.96-2.60$, $P=0.07)$ and no significant association with poor OS was found (RR $1.56,95 \%$ CI $0.87-2.80, P=0.13$ ). Endocrine treatment did not seem to affect the association of cyclin B1 with survival. RR for poor survival was 3.09 (95\% CI 1.68-5.68, $P<0.0005)$ among the patients that had received endocrine treatment and 2.24 (95\% CI $1.21-4.14, P=0.01$ ) among the patients that had not received endocrine treatment. The RRs for metastases were 3.08 (95\% CI $1.83-5.18, P<0.0005)$ and $2.06(95 \%$ CI $1.24-3.43, P=0.006)$, respectively. The association with survival was similar when cyclin B1 was analysed as a continuous value (data not shown). In Figure 1, Kaplan-Meier curves show OS and MFS for cyclin B1 dichotomised at $5.6 \%$.

A multivariate model including TNM status, tumour grade, and ER, PR, Ki67, p53 and HER2 status was constructed to analyse the independent impact of cyclin B1 expression on prognosis. High cyclin B1 had an independent association with poor outcome (Table 4). Among chemotherapy-naive patients, the associations were also stronger in multivariate analysis. With tumour size and nodal status, cyclin B1 was the only factor independently associated with poor MFS (RR 2.31,95\% CI 1.17-4.59, $P=0.016$ ) and OS (RR 1.79, 95\% CI 1.28-4.14, $P=0.04$ ).

\section{DISCUSSION}

This study is so far the most extensive study of cyclin B1 expression in breast cancer and shows that high cyclin B1 expression is a predictor of poor overall and metastasis-free survival. Associations with poor prognosis were stronger among chemotherapy-naive patients. Besides positive nodal status and large tumour size, high cyclin B1 expression was the only independent factor predicting poor OS and MFS among chemotherapy-naive patients. These results suggest that cyclin B1 is a strong independent prognostic marker that could add to accuracy of prognostic evaluation made by traditional prognostic markers and that could easily be adapted for routine use.

Relative risk for poor survival for cyclin B1 was 3.74 and the risk for metastasis 3.51 among chemotherapy-naive patients. In this study, cyclin B1 was a stronger marker of poor prognosis than proliferation markers cyclin A or Ki67 (among chemotherapy-naive patients the $\mathrm{RR}$ for poor survival in univariate analysis was 2.47 for cyclin A and 1.90 for Ki67) and the risk for poor survival was also stronger than that has been previously reported for Ki67 or cyclin A. In multivariate analysis among chemotherapy-naive patients, high cyclin B1 was almost as strong predictor of poor OS as HER2 and PR status, or even tumour grade, and it predicted poor MFS more powerfully than HER2 and PR status or tumour grade. The independent prognostic value of cyclin B1 in this study was as strong as or even stronger than the risks reported for commonly used biological markers in breast cancer. The independent relative risk for histological grade has been reported to be approximately 1.70-3.20 (Simpson et al, 2000; Elston and Ellis, 2002; Volpi et al, 2004), for HER2 2.56 (Joensuu et al, 2003), and for the tumour-related proteolytic factors uPA and PAI-1 in a pooled analysis from 18 patient populations $2.58-3.12$ (Look et al, 2002). In a recent study tumour triple negative status had RR 1.8 for mortality and RR 1.5 for metastasis (Dent et al, 2007). Gene expression profiles have been suggested to add specificity to prognostic evaluation made by traditional and immunohistochemical markers. In a validation study, perhaps the most extensively studied profile, the 70-gene prognosis signature predicted metastases with RR of 2.13 (95\% CI 1.19 3.82 ) and mortality with RR of 2.63 (95\% CI 1.45-4.79) (Buyse et al, 2006). Thus high cyclin B1 might be a biological risk 
Table 4 Cyclin BI expression and survival in multivariable analysis (Cox regression analysis)

\begin{tabular}{|c|c|c|c|}
\hline & $\mathbf{R R}$ & $95 \% \mathrm{Cl}$ & $P$ value \\
\hline \multicolumn{4}{|c|}{ (A) Overall sunvival } \\
\hline \multicolumn{4}{|c|}{ Chemotherapy naive patients $(n=473)$} \\
\hline Nodal status & 3.41 & $1.55-7.49$ & 0.002 \\
\hline Tumour size & 2.87 & $1.95-4.22$ & $<0.0005$ \\
\hline Cyclin BI & 1.80 & $1.28-4.14$ & 0.04 \\
\hline HER2 & 2.03 & $0.82-5.02$ & 0.126 \\
\hline Ki67 & 1.59 & $0.82-3.79$ & 0.20 \\
\hline Progesterone receptor & 1.75 & $0.73-4.17$ & 0.21 \\
\hline Oestrogen receptor & 1.70 & $0.52-5.55$ & 0.38 \\
\hline Grade & 1.43 & $0.78-2.63$ & 0.25 \\
\hline p53 & 1.15 & $0.74-1.80$ & 0.54 \\
\hline \multicolumn{4}{|l|}{ All patients $(n=797)$} \\
\hline Nodal status & 4.17 & $2.33-7.49$ & $<0.0005$ \\
\hline Progesterone receptor & 1.99 & $|.10-3.6|$ & 0.02 \\
\hline HER2 & 1.91 & $1.15-3.18$ & 0.01 \\
\hline Tumour size & 1.87 & $1.47-2.37$ & $<0.0005$ \\
\hline Grade & 1.79 & $1.14-2.79$ & 0.01 \\
\hline Cyclin BI & 1.83 & $0.99-3.40$ & 0.05 \\
\hline p53 & 1.15 & $0.91-1.47$ & 0.25 \\
\hline Ki67 & 1.08 & $0.62-1.25$ & 0.28 \\
\hline Oestrogen receptor & 0.89 & $0.45-1.76$ & 0.74 \\
\hline \multicolumn{4}{|l|}{ (B) Metastasis-free survival } \\
\hline \multicolumn{4}{|c|}{ Chemotherapy naive patients ( $n=473$ ) } \\
\hline Nodal status & 2.76 & $1.48-5.13$ & 0.001 \\
\hline Cyclin BI & 2.31 & $1.17-4.59$ & 0.02 \\
\hline Tumour size & 1.91 & $1.35-2.72$ & $<0.0005$ \\
\hline Grade & 1.44 & $0.90-2.32$ & 0.13 \\
\hline Ki67 & 1.39 & $0.82-1.65$ & 0.35 \\
\hline Progesterone receptor & 1.27 & $0.60-2.67$ & 0.53 \\
\hline Oestrogen receptor & 1.10 & $0.36-3.36$ & 0.87 \\
\hline HER2 & 1.10 & $0.46-2.63$ & 0.82 \\
\hline p53 & 1.06 & $0.72-1.55$ & 0.79 \\
\hline \multicolumn{4}{|l|}{ All patients $(n=797)$} \\
\hline Nodal status & 2.97 & $1.87-4.67$ & $<0.0005$ \\
\hline Cyclin BI & 1.68 & $1.02-2.74$ & 0.04 \\
\hline Tumour size & 1.64 & $1.33-2.03$ & $<0.0005$ \\
\hline Grade & 1.63 & $1.14-2.32$ & 0.008 \\
\hline HER2 & 1.46 & $0.92-2.31$ & 0.11 \\
\hline Progesterone receptor & 1.39 & $0.84-2.31$ & 0.20 \\
\hline Ki67 & 1.26 & $0.67-1.52$ & 0.26 \\
\hline p53 & 1.14 & $0.92-1.41$ & 0.23 \\
\hline Oestrogen receptor & 0.81 & $0.45-1.47$ & 0.49 \\
\hline
\end{tabular}

Abbreviations: $\mathrm{RR}=$ relative risk; $95 \% \mathrm{Cl}=95 \%$ confidence interval. Cyclin $\mathrm{BI}$ dichotomised at 7 th percentile $(5.6 \%)$

predictor as strong as the 70-gene profile and more easily adapted for routine use.

Our study is the largest so far showing the association of high cyclin B1 and shorter survival in breast cancer. One earlier smaller study with stage I- II tumours did not show any association (Peters et al, 2004), one with 109 tumours showed association with only nuclear staining (Suzuki et al, 2007) and one with 73 tumours showed a significant association (Winters et al, 2001). In the hitherto largest study of 332 tumours, all $\mathrm{N}$-negative, cyclin B1 was associated with poor prognosis but not in multivariate analysis including Ki67 (Rudolph et al, 2003), and when 273 tumours with only surgery and postoperative radiation were analysed, cyclin B1 was prognostic only in premenopausal patients (Kühling et al, 2003). The limitations of our study include the retrospective setting of the study and the heterogeneity of the patient material concerning adjuvant treatments. Conclusions are, however, in line with the ones suggested by earlier smaller studies, and we feel the role of cyclin B1 as prognostic factor in breast cancer deserves to be further validated, utilising specifically the methods and cut-offs designed in this study.

The correlations between cyclin B1 and other tumour features show that high cyclin B1 expression is common among tumours with an aggressive phenotype. The association of high cyclin B1 expression with large tumour size, positive nodal status, high grade, and ER and PR negativity is similar to previous reported data (Kühling et al, 2003; Rudolph et al, 2003). One smaller study did not find any correlation to N, T, ER and p53 status, but the small sample size (73 tumours) may explain this discrepancy (Winters et al, 2001). In our study, again supported by earlier results, cyclin B1 was strongly associated with high grade and high Ki67, cyclin A and E expression (Winters et al, 2001). We also show that high cyclin $\mathrm{B} 1$ associated with p53 positivity. This is biologically relevant because p53 controls the cell cycle via cyclin B1 (Innocente et al, 1999). Thus multiple biological factors related with an active cell cycle are intercorrelated. Cyclin B1 expression correlated significantly with HER2 positivity and this, to our knowledge, has not been reported earlier and is consistent with an aggressive phenotype. One can speculate on whether the prognostic impact of cyclin B1 reflects only a high tumour proliferation rate or whether high cyclin B1 may reflect also other biological properties of the tumour. In our patients cyclin B1 seems to be a stronger prognostic factor than cyclin A or Ki67. In our material (data not shown), a high cyclin A or Ki67 score was associated with a shorter time to first event among patients eventually developing metastases, whereas the median time to development of metastases was similar in patients with high and low cyclin B1 score. This implies cyclin B1 expression may not be a pure proliferation marker but reflects also other features, for exqample, genomic instability of the tumour as suggested by previous studies (Innocente et al, 1999; Shen et al, 2004). By analysing both cytoplasmic and nuclear cyclin B1 expression in this study, both aberrant and physiologic cyclin B1 expression were probably included because the cyclin B1/CDK1 complex is relocated to the nucleus only in the beginning of the $\mathrm{M}$ phase.

In conclusion, this study shows that cyclin B1 expression is an independent predictor of poor overall and metastasis-free survival in breast cancer. If verified the results of this study suggest cyclin B1 immunohistochemistry is a method that could easily be adapted for routine use as a prognostic marker in breast cancer. The generally lower risk ratios for mortality or metastases in patients given adjuvant chemotherapy suggest that high cyclin B1 score may indicate an enhanced sensitivity to chemotherapy.

\section{ACKNOWLEDGEMENTS}

We acknowledge all the patients participating our study and thank Nina Puolakka for working with the patient data, Majlis Book for technical assistance and the Finnish Cancer Registry for cancer data. This study was supported by the Finnish Medical Foundation (Finska Läkaresällskapet), the Finnish Cancer Organizations, the Helsinki University Hospital Research Fund, the Academy of Finland (110663) and the Sigrid Juselius Fund.

\section{REFERENCES}

Aaltonen K, Ahlin C, Amini RM, Salonen L, Fjällskog ML, Heikkilä P, Nevanlinna H, Blomqvist C (2006) Reliability of cyclin A assessment on tissue microarrays in breast cancer compared to conventional histological slides. Br J Cancer 94: 1697 - 1702 
Ahlin C, Aaltonen K, Amini RM, Nevanlinna H, Fjällskog ML, Blomqvist C (2007) Ki67 and cyclin A as prognostic factors in early breast cancer. What are the optimal cut-off values? Histopathology 51: 491-498

Bast RC, Ravdin P, Hayes DF, Bates S, Fritsche Jr H, Jessup JM, Kemeny N, Locker GY, Mennel RG, Somerfield MR (2001) 2000 update of recommendations for the use of tumor markers in breast and colorectal cancer: clinical practice guidelines of the American society of clinical oncology. J Clin Oncol 19: 1865-1878

Bryant J, Fisher B, Gunduz N, Costantino JP, Emir B (1998) S-phase fraction combined with other patient and tumor characteristics for the prognosis of node-negative, estrogen-receptor-positive breast cancer. Breast Cancer Res Treat 51: 239-253

Buyse M, Loi S, van't Veer L, Viale G, Delorenzi M, Glas AM, d'Assignies MS, Bergh J, Lidereau R, Ellis P, Harris A, Bogaerts J, Therasse P, Floore A, Amakrane M, Piette F, Rutgers E, Sotiriou C, Cardoso F, Piccart MJ, TRANSBIG Consortium (2006) Validation and clinical utility of a 70-gene prognostic signature for women with node-negative breast cancer. J Natl Cancer Inst 98: 1183-1192

Dent R, Trudeau M, Pritchard KI, Hanna WM, Kahn HK, Sawka CA, Lickley LA, Rawlinson E, Sun P, Narod SA (2007) Triple-negative breast cancer: clinical features and patterns of recurrence. Clin Cancer Res 13: $4429-4434$

Dettmar P, Harbeck N, Thomssen C, Pache L, Ziffer P, Fizi K, Jänicke F, Nathrath W, Schmitt M, Graeff H, Höfler H (1997) Prognostic impact of proliferation-associated factors MIB1 (ki-67) and S-phase in nodenegative breast cancer. Br J Cancer 75: 1525-1533

Eerola H, Blomqvist C, Pukkala E, Pyrhönen S, Nevanlinna H (2000) Familial breast cancer in southern Finland: how prevalent are breast cancer families and can we trust the family history reported by patients? Eur J Cancer 36: 1143-1148

Eerola H, Heikkila P, Tamminen A, Aittomäki K, Blomqvist C, Nevanlinna $\mathrm{H}$ (2005) Histopathological features of breast tumours in BRCA1, BRCA2 and mutation-negative breast cancer families. Breast Cancer Res 7: R93 - 100

Elston CW, Ellis IO (2002) Pathological prognostic factors in breast cancer. I. The value of histological grade in breast cancer: experience from a large study with long-term follow-up. Histopathology 41: 154-161

Ikuerowo SO, Kuczyk MA, Mengel M, van der Heyde E, Shittu OB, Vaske B, Jonas U, Machtens S, Serth J (2006) Alteration of subcellular and cellular expression patterns of cyclin B1 in renal cell carcinoma is significantly related to clinical progression and survival of patients. Int J Cancer 119: $867-874$

Innocente SA, Abrahamson JL, Cogswell JP, Lee JM (1999) p53 regulates a G2 checkpoint through cyclin B1. Proc Natl Acad Sci USA 96: 2147-2152

Joensuu H, Isola J, Lundin M, Salminen T, Holli K, Kataja V, Pylkkänen L, Turpeenniemi-Hujanen T, von Smitten K, Lundin J (2003) Amplification of erbB2 and erbB2 expression are superior to estrogen receptor status as risk factors for distant recurrence in pT1N0M0 breast cancer: a nationwide population-based study. Clin Cancer Res 9: 923-930

Kawamoto H, Koizumi H, Uchikoshi T (1997) Expression of the G2-M checkpoint regulators cyclin $\mathrm{B} 1$ and cdc2 in nonmalignant and malignant human breast lesions: immunocytochemical and quantitative image analyses. Am J Pathol 150: 15-23

Kilpivaara O, Bartkova J, Eerola H, Syrjäkoski K, Vahteristo P, Lukas J, Blomqvist C, Holli K, Heikkilä P, Sauter G, Kallioniemi OP, Bartek J, Nevanlinna H (2005) Correlation of CHEK2 protein expression and c.1100delC mutation status with tumor characteristics among unselected breast cancer patients. Int J Cancer 113: $575-580$

Kühling H, Alm P, Olsson H, Fernö M, Baldetorp B, Parwaresch R, Rudolph P (2003) Expression of cyclin E, A and B and prognosis in lymph nodenegative breast cancer. J Pathol 199: 424-431

Lassus H, Leminen A, Vayrynen A, Cheng G, Gustafsson JA, Isola J, Butzow $\mathrm{R}$ (2004) ERBB2 amplification is superior to protein expression status in predicting patient outcome in serous ovarian carcinoma. Gynecol Oncol 92: $31-39$

Look MP, van Putten WL, Duffy MJ, Harbeck N, Christensen IJ, Thomssen C, Kates R, Spyratos F, Fernö M, Eppenberger-Castori S, Sweep CG, Ulm K, Peyrat JP, Martin PM, Magdelenat H, Brünner N, Duggan C, Lisboa BW, Bendahl PO, Quillien V, Daver A, Ricolleau G, Meijer-van Gelder ME, Manders P, Fiets WE, Blankenstein MA, Broët P, Romain $S$, Daxenbichler G, Windbichler G, Cufer T, Borstnar S, Kueng W, Beex LV, Klijn JG, O'Higgins N, Eppenberger U, Jänicke F, Schmitt M, Foekens JA (2002) Pooled analysis of prognostic impact of urokinase-type plasminogen activator and its inhibitor PAI-1 in 8377 breast cancer patients. J Natl Cancer Inst 94: 116-128
Murakami H, Furihata M, Ohtsuki Y, Ogoshi S (1999) Determination of the prognostic significance of cyclin B1 overexpression in patients with esophageal squamous cell carcinoma. Virchows Arch 434: 153-158

Nozoe T, Korenaga D, Kabashima A, Ohga T, Saeki H, Sugimachi K (2002) Significance of cyclin B1 expression as an independent prognostic indicator of patients with squamous cell carcinoma of the esophagus. Clin Cancer Res 8: 817-822

Paik S, Shak S, Tang G, Kim C, Baker J, Cronin M, Baehner FL, Walker MG, Watson D, Park T, Hiller W, Fisher ER, Wickerham DL, Bryant J, Wolmark N (2004) A multigene assay to predict recurrence of tamoxifentreated, node-negative breast cancer. $N$ Engl J Med 351: 2817-2826

Peters MG, Vidal del Carmen M, Gimenez L, Mauro L, Armanasco E, Cresta C, Bal de Kier Joffe E, Puricelli L (2004) Prognostic value of cell cycle regulator molecules in surgically resected stage I and II breast cancer. Oncol Rep 12: $1143-1150$

Pines J, Hunter T (1990) Human cyclin A is adenovirus E1A-associated protein p60 and behaves differently from cyclin B. Nature 346: 760-763

Rudolph P, Kühling H, Alm P, Fernö M, Baldetorp B, Olsson H, Parwaresch R (2003) Differential prognostic impact of the cyclins $E$ and $B$ in premenopausal and postmenopausal women with lymph-node negative breast cancer. Int J Cancer 105: 674-680

Shen M, Feng Y, Gao C, Tao D, Hu J, Reed E, Li QQ, Gong J (2004) Detection of cyclin b1 expression in $\mathrm{g}(1)$-phase cancer cell lines and cancer tissues by postsorting western blot analysis. Cancer Res 64: $1607-1610$

Sherr CJ (1996) Cancer cell cycles. Science 274: $1672-1677$

Simpson JF, Gray R, Dressler LG, Cobau CD, Falkson CI, Gilchrist KW, Pandya KJ, Page DL, Robert NJ (2000) Prognostic value of histologic grade and proliferative activity in axillary node-positive breast cancer: results from the Eastern Cooperative Oncology Group Companion Study, EST 4189. J Clin Oncol 18: 2059-2069

Soria JC, Jang SJ, Khuri FR, Hassan K, Liu D, Hong WK, Mao L (2000) Overexpression of cyclin B1 in early-stage non-small cell lung cancer and its clinical implication. Cancer Res 60: 4000-4004

Suzuki T, Urano T, Miki Y, Moriya T, Akahira J, Ishida T, Horie K, Inoue S, Sasano H (2007) Nuclear cyclin B1 in human breast carcinoma as a potent prognostic factor. Cancer Sci 98: 644-651

Syrjäkoski K, Vahteristo $\mathrm{P}$, Eerola $\mathrm{H}$, Tamminen A, Kivinummi K, Sarantaus L, Holli K, Blomqvist C, Kallioniemi OP, Kainu T, Nevanlinna H (2000) Population-based study of BRCA1 and BRCA2 mutations in 1035 unselected Finnish breast cancer patients. J Natl Cancer Inst 92: $1529-1531$

Takeno S, Noguchi T, Kikuchi R, Uchida Y, Yokoyama S, circ;ller W (2002) Prognostic value of cyclin $\mathrm{B} 1$ in patients with esophageal squamous cell carcinoma. Cancer 94: 2874-2881

Tanner M, Gancberg D, Di Leo A, Larsimont D, Rouas G, Piccart MJ, Isola J (2000) Chromogenic in situ hybridization: a practical alternative for fluorescence in situ hybridization to detect HER-2/neu oncogene amplification in archival breast cancer samples. Am J Pathol 157: $1467-1472$

Tommiska J, Eerola H, Heinonen M, Salonen L, Kaare M, Tallila J, Ristimäki A, von Smitten K, Aittomäki K, Heikkilä P, Blomqvist C, Nevanlinna H (2005) Breast cancer patients with p53 Pro72 homozygous genotype have a poorer survival. Clin Cancer Res 11: 5098-5103

van de Vijver MJ, He YD, van't Veer LJ, Dai H, Hart AA, Voskuil DW, Schreiber GJ, Peterse JL, Roberts C, Marton MJ, Parrish M, Atsma D, Witteveen A, Glas A, Delahaye L, van der Velde T, Bartelink $\mathrm{H}$, Rodenhuis S, Rutgers ET, Friend SH, Bernards R (2002) A geneexpression signature as a predictor of survival in breast cancer. $N$ Engl Med 347: 1999-2009

Van't Veer LJ, Dai H, van de Vijver MJ, He YD, Hart AA, Mao M, Peterse HL, van der Kooy K, Marton MJ, Witteveen AT, Schreiber GJ, Kerkhoven RM, Roberts C, Linsley PS, Bernards R, Friend SH (2002) Gene expression profiling predicts clinical outcome of breast cancer. Nature 415: 530-536

Volpi A, Bacci F, Paradiso A, Saragoni L, Scarpi E, Ricci M, Aldi M, Bianchi S, Muretto P, Nuzzo F, Simone G, Mangia A, Schittulli F, Amadori D (2004) Prognostic relevance of histological grade and its components in node-negative breast cancer patients. Mod Pathol 17: 1038-1044

Winters ZE, Hunt NC, Bradburn MJ, Royds JA, Turley H, Harris LA, Norbury CJ (2001) Subcellular localisation of cyclin B, Cdc2 and p21(WAF1/CIP1) in breast cancer, association with prognosis. Eur $J$ Cancer 37: 2405-2412

Yoshida T, Tanaka S, Mogi A, Shitara Y, Kuwano H (2004) The clinical significance of cyclin B1 and Weel expression in non-small-cell lung cancer. Ann Oncol 15: 252-256 